\title{
Corticosteroid-Induced Adrenal Insufficiency in Africa: Report of Nine Cases at the Internal Medicine/Endocrinology-Diabetology Department of Pikine NHC
}

\author{
Nafy Ndiaye, Ngone Diaba Diack, Yakham Mohamed Leye, Abdou Dieng, Mamadou Ba, \\ Abdoulaye Leye \\ Internal Medicine/Endocrinology-Diabetology Department, Teaching Hospital of Pikine, Dakar, Senegal \\ Email: fyfynami@yahoo.fr
}

How to cite this paper: Ndiaye, N., Diack, N.D., Leye, Y.M., Dieng, A., Ba, M. and Leye, A. (2020) Corticosteroid-Induced Adrenal Insufficiency in Africa: Report of Nine Cases at the Internal Medicine/Endocrinology-Diabetology Department of Pikine NHC. Open Journal of Endocrine and Metabolic Diseases, 10, 155-163.

https://doi.org/10.4236/ojemd.2020.1012015

Received: November 13, 2020

Accepted: December 26, 2020

Published: December 29, 2020

Copyright $\odot 2020$ by author(s) and Scientific Research Publishing Inc. This work is licensed under the Creative Commons Attribution International License (CC BY 4.0).

http://creativecommons.org/licenses/by/4.0/

\begin{abstract}
Introduction: Prolonged corticosteroid therapy is labeled as the main cause of corticotropic adrenal insufficiency. However, the current frequency of this complication remains unknown. The objective of our study was to assess its epidemiologic, diagnostic, therapeutic, and evolutionary aspects of our practice. Methodology: A 60-month retrospective study was performed from May 2014 to April 2020 in the Pikine National Hospital Centre. Data were obtained from the medical records of patients with corticosteroid-induced adrenal insufficiency. Epidemiologic, diagnostic, therapeutic, and evolutionary parameters, and data related to corticotherapy were recorded. Patients with basal plasma cortisol levels $<50 \mathrm{ng} / \mathrm{ml}$ or a plasma cortisol level less than double of the basal cortisolaemia one $\mathrm{H}$ after administration of synachtene 250 were included. Results: Medical records were obtained from nine patients, comprising six women and three men. The mean age of the patients was 48 years. Long-term corticosteroid therapy was used for self-medication in six patients and artificial bleaching in the remaining three patients. Betamethasone was the most commonly used drug in four patients, followed by clobetasol in three patients. Corticotropic insufficiency was revealed as a result of acute decompensation in five patients. All patients presented with a pseudo-cushingoid pattern. Diagnosis of corticotropic adrenal insufficiency was confirmed by measuring basal plasma cortisol levels of $<50 \mathrm{ng} / \mathrm{ml}$ in seven patients. A standard Synachtene test was performed on two patients. All patients benefited from hydrocortisone supplementation. In the short-term, the outcome was unremarkable for all patients. Medium and long-term progression could be assessed in only three patients. Two patients showed persistent suppression with a 6- and 9-month follow-up. One patient was readmitted after one month
\end{abstract}


due to an adrenal crisis following voluntary discontinuation of hydrocortisone treatment. Conclusion: Post-corticosteroid therapy adrenal insufficiency remains a concern in our practice and is favoured by the non-compliance of providing rules by pharmacies and the parallel drug market.

\section{Keywords}

Adrenal Insufficiency, Corticotherapy, Artificial Depigmentation, Self-Medication

\section{Introduction}

Since the beginning of their use in the 1950s, the occurrence of adrenal insufficiency in patients who recently discontinued corticosteroid treatment has been reported. Prolonged corticosteroid therapy is believed to be the primary cause of corticotropic insufficiency [1]. Chronic use of corticosteroids inhibits the function of the hypothalamic-pituitary-adrenal axis through negative feedback, which may cause adrenal insufficiency, even after discontinuation of corticosteroid treatment. Therefore, patients may require glucocorticoid replacement therapy after chronic corticosteroid use in periods of stress, such as trauma, surgery, or acute illness, until full recovery of adrenal function. In some cases, chronic replacement with physiological doses of glucocorticoid therapy is indicated; however, the literature is scarce [2]. The clinical course of cortico-induced adrenal insufficiency is non-specific and often pauci-symptomatic. It differs from primary adrenal insufficiency through the absence of melanoderma and mineralocorticoid deficiency-related signs [3]. Our study aimed to evaluate the epidemiologic, diagnostic, therapeutic, and evolutionary aspects of corticosteroid-induced adrenal insufficiency.

\section{Methodology}

We conducted a retrospective study over a 6-year period from May 2014 to April 2020 at the Pikine National Hospital Centre. Patients presenting in the department during the study period were selected and their respective data from computer files. The indexes of patients in whom the diagnosis of adrenal insufficiency after corticosteroid therapy was retained were listed. After obtaining authorisation to access patient archives, we selected all files from patients with adrenal insufficiency confirmed by hormonal assays after discontinuing corticosteroid therapy.

Patients with a baseline cortisol level $>130 \mathrm{ng} / \mathrm{ml}$ were excluded from the study. For patients with a baseline cortisolaemia between 50 and $130 \mathrm{ng} / \mathrm{ml}$, diagnosis was made with a one-hour post-cortisolaemia following synacthene administration was less than double the cortisolaemia at T0.

After obtaining patient consent, epidemiologic, diagnostic, therapeutic, and 
evolutionary parameters, as well as data related to corticotherapy, were collected. Patients with basal plasma cortisol levels $<50 \mathrm{ng} / \mathrm{ml}$ or plasma cortisol levels less than double that of the basal cortisolaemia one-hour post-administration of synachtene 250 were considered.

Data input and processing were performed using Microsoft Excel Software.

\section{Results}

Nine medical records of patients experiencing adrenal insufficiency due to the corticotropic axis suppression were collected.

\subsection{Epidemiological Data}

The mean age of patients was 48 years, ranging from 32 to 58 years. The cohort comprised of six women and three men.

\subsection{Data on Corticosteroid Therapy}

Corticosteroid therapy was prescribed for four patients, but the latter had voluntarily continued the treatment. In two patients, corticosteroid therapy was purchased over the counter. For three patients, corticosteroid therapy was used for artificial bleaching. The total duration of corticosteroid exposure could only be determined in patients undergoing oral corticosteroid therapy and was difficult to assess in patients performing artificial bleaching. These patients used dermocorticoids in alternation with other lightening products based on hydroquinone or fruit acids. The time between the cessation of corticosteroid therapy and the appearance of adrenal insufficiency features ranged between one to five months. Betamethasone was the most commonly used corticosteroid in four patients, followed by clobetasol in three patients. All patients abruptly withdrew corticosteroid use. This was motivated by weight gain in four patients. In one patient using dermocorticoids, the underlying reason for withdrawal was the occurrence of necrotizing dermohypoderma. Table 1 shows the distribution of patients according to the corticosteroid therapy modalities.

\subsection{Clinical Data}

Corticotropic axis suppression was revealed via an adrenal crisis in five patients and slow adrenal insufficiency features in three patients. A female patient referred by her company physician for an examination of the corticotropic axis presented no symptoms of acute or chronic adrenal insufficiency. In patients with initial acute decompensation, the triggering factor was found in only three of five patients and was attributed to dysenteric syndrome, hypercalcaemia crisis on an underlying primary hyperparathyroidism condition, and suppurative myositis. The clinical course of slow adrenal insufficiency was limited to persistent asthenia in all three patients. Diagnosis was mainly suspected based on cortisonic impregnation signs, with a cushing-like aspect noted in all patients (Figure 1 and Figure 2) and recent prolonged corticotherapy withdrawal. Other complications of corticotherapy were skin fragility, which was noted in patients 
Table 1. Distribution of patients according to corticosteroid therapy modalities.

\begin{tabular}{|c|c|c|c|c|c|}
\hline Patients & $\begin{array}{c}\text { Corticotherapy } \\
\text { initiation }\end{array}$ & $\begin{array}{c}\text { Reason for } \\
\text { corticotherapy }\end{array}$ & $\begin{array}{l}\text { Corticosteroid } \\
\text { drug }\end{array}$ & $\begin{array}{l}\text { Duration } \\
\text { of use }\end{array}$ & $\begin{array}{c}\text { Time of } \\
\text { symptoms } \\
\text { appearance } \\
\text { after } \\
\text { withdrawal }\end{array}$ \\
\hline No. 1 & $\begin{array}{c}\text { Medical } \\
\text { prescription }\end{array}$ & $\begin{array}{l}\text { Rheumatoid } \\
\text { polyarthritis }\end{array}$ & Prednisone & 14 years & Non-specified \\
\hline No. 2 & $\begin{array}{c}\text { Medical } \\
\text { prescription }\end{array}$ & $\begin{array}{l}\text { Allergic features } \\
\text { on underlying } \\
\text { atopic condition }\end{array}$ & Betamethasone & 4 years & $\begin{array}{c}\text { Asymptomatic } \\
\text { at the time of } \\
\text { diagnosis }\end{array}$ \\
\hline No. 3 & $\begin{array}{c}\text { Medical } \\
\text { prescription }\end{array}$ & Lombosciatalgia & Betamethasone & 2 years & Non-specified \\
\hline No. 4 & $\begin{array}{c}\text { Medical } \\
\text { prescription }\end{array}$ & Asthma & Betamethasone & 5 years & Non-specified \\
\hline No. 5 & Self-medication & $\begin{array}{l}\text { Lombalgies } \\
\text { chroniques }\end{array}$ & Dexamethasone & 2 years & 4 months \\
\hline No. 6 & Self-medication & Asthma & Betamethasone & 2 years & 5 months \\
\hline No. 7 & - & $\begin{array}{l}\text { Artificial } \\
\text { bleaching }\end{array}$ & Clobetasol & - & 1 month \\
\hline No. 8 & - & $\begin{array}{l}\text { Artificial } \\
\text { bleaching }\end{array}$ & Clobetasol & - & 2 months \\
\hline No. 9 & - & $\begin{array}{l}\text { Artificial } \\
\text { bleaching }\end{array}$ & Clobetasol & - & 5 months \\
\hline
\end{tabular}

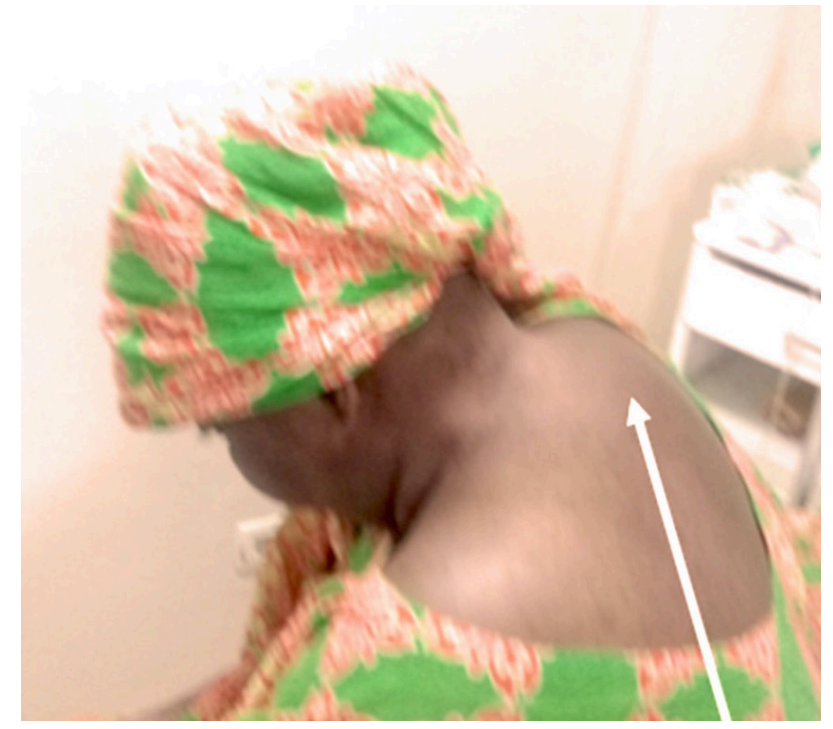

Figure 1. "Buffalo neek" in a 45-year-old patient undergoing artificial depigmentation.

undergoing artificial bleaching. A 32-year-old patient undergoing artificial bleaching since their teen years presented with aseptic osteonecrosis of the femoral head (Figure 3). 


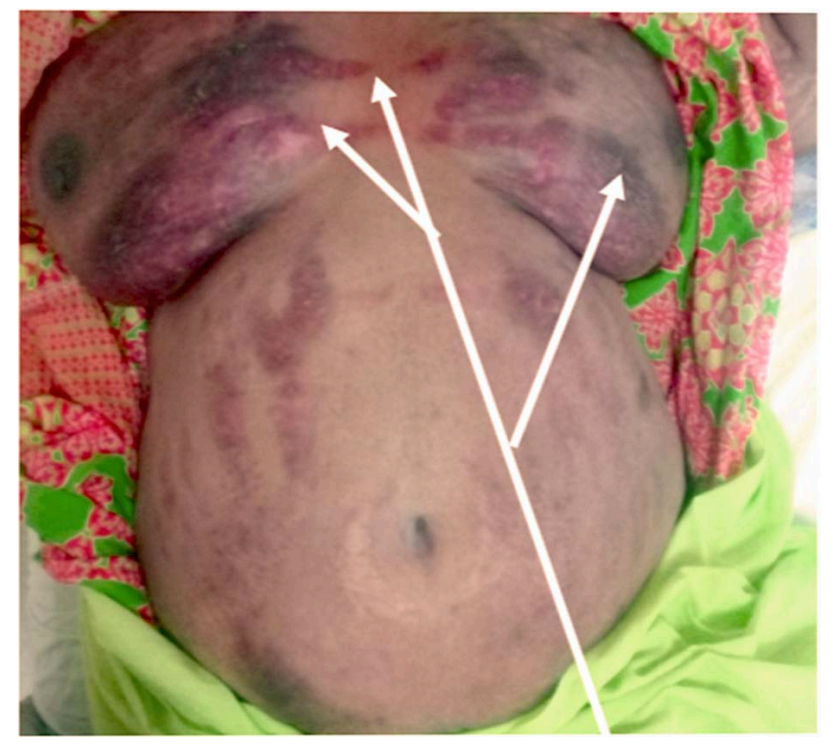

Figure 2. Purple-red stretch marks.

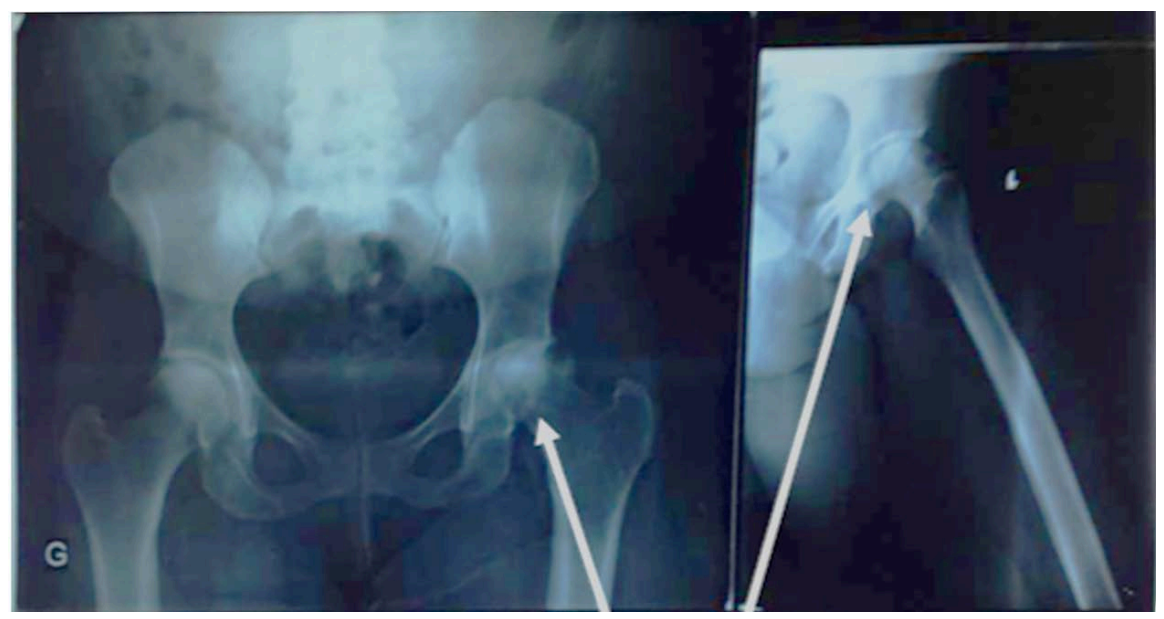

Figure 3. X-ray of the pelvis showing osteonecrosis of the femoral head in a 32-year-old patient undergoing skin lightening since adolescence with prolonged use of topical corticosteroids.

\subsection{Laboratory Findings}

The mean basal plasma cortisol levels were $17.24 \mathrm{ng} / \mathrm{ml}$, widely ranging from 1 to $64 \mathrm{ng} / \mathrm{ml}$. The morning cortisolaemia was $\leq 50 \mathrm{ng} / \mathrm{ml}$ in seven patients. A standard Synachtene test was performed in two patients, facilitating corticotropic suppression.

Hypokalemia was noted in all patients admitted with adrenal crisis. In one patient, hypokalemia was associated with hyponatremia.

\subsection{Treatment}

All patients received hydrocortisone supplementation. Initially, supplementation was parenteral for the first two to three days in patients with acute decompensation. Hydrocortisone supplementation was associated with the correction of elec- 
trolyte disorders and management of the decompensation factor. Maintenance therapy with hydrocortisone at a dosage of $20-30 \mathrm{mg}$ /day divided into two doses was initiated in eight patients. A patient with rheumatoid arthritis was not placed under hydrocortisone maintenance therapy due to the reintroduction of prednisone (20 mg/day).

\subsection{Evolution}

In the short-term, the evolution was unremarkable for all patients after the initiation of treatment. Long-term evolution could be assessed in only three patients. In one patient who had been on betamethasone for two years with a 9-month follow-up, suppression was still present after the Synachtene test; however, the patient experienced eczema, resulting in the reintroduction of corticosteroids. In an additional patient was under dexamethasone therapy, the braking persisted after 6 months before he was lost. One patient who a patient practicing artificialbleaching was readmitted a month later for acute episodes following a therapeutic rupture.

\section{Discussion}

Since the beginning of corticosteroid use, adrenal insufficiency secondary to general corticosteroid therapy has been described as isolated clinical cases with often fatal outcomes. The modalities of corticosteroid therapy differed from those of present, namely higher glucocorticoid doses, lack of knowledge about the risk of secondary adrenal insufficiency leading to diagnosis delay, and absence of perioperative precautions [1]. Symptomatic corticosteroid-induced adrenal insufficiency has become a very rare event due to improved knowledge of the risk of post-corticosteroid-induced adrenal insufficiency and suitable prevention measures [4]. All patients undergoing corticosteroid therapy undergo adrenal insufficiency risk [5]. The inhibition of the corticotropic axis induced by glucocorticoids is related to their negative pituitary and hypothalamic feedback control. Suppression of the corticotropic axis may be more likely after high doses and longterm glucocorticoid treatment. However, cases of adrenal insufficiency with an equivalent dosage of $5 \mathrm{mg} /$ day of prednisone or after two weeks of treatment have been reported. Other factors associated with the onset of corticotropic axis deceleration involve the duration of glucocorticoid action (intermediate- and longacting steroids have a continuous effect on the corticotropic axis) and the time of glucocorticoid administration (the dose administered in the evening suppresses the natural circadian rhythm more than the same dose administered in the morning). Some genetic variations have been associated with variability in corticotropic axis sensitivity and responsiveness. The most frequent gene variants are identified for monoamine oxidase A, catechol O-methyltransferase, the 2-adrenergic receptor, and angiotensin-converting enzyme. Other related genes are also implicated, including the $\mu$ opioid receptor, the GABAA receptor, the serotonin transporter, and brain-derived neurotrophic factor [4] [6]. In all our patients, corti- 
costeroid therapy was abruptly discontinued. Six patients self-medicated or voluntarily continued therapy. In the remaining three patients, voluntary corticosteroid therapy was used for artificial bleaching. The few cases reported in the literature from studies in Africa also occur in the same aetiological circumstances, namely self-medication and artificial bleaching [7] [8].

Plasma cortisol levels can be lowered even after a short local corticosteroid therapy [8] [9]. However, hypothalamic-pituitary-adrenal axis suppression with adrenal crisis secondary to dermocorticoid treatment withdrawal is very rare. It occurs after prolonged and often abusive use of powerful dermocorticoids over a large area. Children, especially infants, are at greater risk due to a high ratio of body surface area over weight [10]. In Sub-Saharan Africa, sporadic cases have been reported among women who perform voluntary artificial bleaching [8] [9] [10] [11]. This practice is also observed in genetically pigmented populations living in Europe or the United States [12]. The systemic effects following prolonged application of large quantities of dermocorticoids will correspond to general corticosteroid therapy. The quantities of clobetasol propionate often exceeded $30 \mathrm{~g} /$ month, the dose at which systemic effects appear [8] [11] [13].

Biological abnormalities during or secondary to corticosteroid therapy are almost consistent. Clinical events are uncommon and mostly occur as a crisis during stress (surgery, infection) on an underlying latent or unknown adrenal insufficiency [4] [5] [6]. In our study, the reasons were an adrenal crisis in five of nine patients.

Plasma cortisol measurement in the morning may be sufficient to classify some patients in "insufficient corticotropic function" or "normal corticotropic function" groups without the need for further testing. In practice, a basal plasma cortisol levels $<50 \mathrm{ng} / \mathrm{ml}$ is the best predictor of corticotropic insufficiency, and basal plasma cortisol levels $>130 \mathrm{ng} / \mathrm{ml}$ suggests normal adrenal function. Between these two thresholds, a synachtene test should be performed [3] [14]. In the patients in the present study, cortisolaemia was sufficient to diagnose seven patients. The synachtene test was performed on two patients.

In evolutionary terms, the affinity of the synthetic glucocorticoid for the glucocorticoid receptor is correlated with the inhibitory effect on the corticotropic axis [4] [15]. However, this positive correlation established between a measurement made in vitro and an inhibition observed in vivo is modified by the bioavailability of the glucocorticoid. Thus, the affinity of dexamethasone in vitro for the glucocorticoid receptor is seven times greater than that of cortisol; however, its' in vivo inhibitory effect on the corticotropic axis is 15 to 30 times greater than that of cortisol. The bioavailability of glucocorticoids is, therefore, an important factor [15]. This could explain the delayed recovery of corticotropic function in the two patients under dexamethasone and betamethasone therapy. The main limitation of our study is its retrospective nature with missing data, in particular, the long-term evolution that could only be assessed in three patients. A longitudinal multicenter study with a larger cohort will provide a better ap- 
preciation of epidemiological aspects in our practice.

\section{Conclusion}

Anecdotal adrenal insufficiencies after corticosteroid therapy in Western countries remain a concern in our practice. They are most often secondary to selfmedication with powerful corticosteroids. Artificial bleaching with dermocorticoids is a particularity of sub-Saharan Africa. Corticosteroid-induced adrenal insufficiency has a good prognosis in the event that physicians are informed. Prevention remains the best treatment modality and involves fighting against parallel drug markets and raising pharmacists' awareness of the need to respect drug tables and the validity of prescriptions. Therapeutic education is also a cornerstone for its management.

\section{Acknowledgements}

Editorial assistance, in the form of language editing and correction, was provided by Xpert Scientific Editing and Consulting Services.

\section{Conflicts of Interest}

The authors declare no conflicts of interest regarding the publication of this paper.

\section{References}

[1] Fraser, C.G. and Preuss, F.S. (1952) Adrenal Atrophy and Irreversible Shock Associated with Cortisone Therapy. Journal of the American Medical Association, 149, 1542-1543. https://doi.org/10.1001/jama.1952.72930340001009

[2] Broersen, L.H., Pereira, A.M., Jørgensen, J.O. and Dekkers, O.M. (2015) Adrenal Insufficiency in Corticosteroids Use: Systematic Review and Meta-Analysis. The Journal of Clinical Endocrinology \& Metabolism, 100, 2171-2180. https://doi.org/10.1210/jc.2015-1218

[3] Goichot, B., Vinzio, S., Luca, F. and Schlienger, J.L. (2007) Glucocorticoid-Induced Adrenal Insufficiency. La Presse Médicale, 36, 1065-1071. https://doi.org/10.1016/j.lpm.2006.11.014

[4] Guerrero Pérez, F., Marengo, A.P. and Villabona Artero, C. (2017) The Unresolved Riddle of Glucocorticoid Withdrawal. Journal of Endocrinological Investigation, 40, 1175-1181. https://doi.org/10.1007/s40618-017-0691-1

[5] Fardet, L., Kassar, A., Cabane, J. and Flahault, A. (2007) Corticosteroid Induced Adverse events in Adults: Frequency, Screening and Prevention. Drug Safety, 30, 861-881. https://doi.org/10.2165/00002018-200730100-00005

[6] Perret, J.L., Sane, M., Gning, S., Ba, K. and Rohou, G. (2001) Partial Functional Hypothalamo-Pituitary-Adrenal Inertia with Bleaching Agents in Senegal. Bulletin de la Société de Pathologie Exotique, 94, 249-252.

[7] Zomalheto, Z., Dossou-yovo, H., Zossoungbo, F. and Avimadjè, M. (2015) Prevalence of Complications of Corticosteroids Therapy among West African Consulting in Rheumatology. Pan African Medical Journal, 21, Article No. 304. https://doi.org/10.11604/pamj.2015.21.304.5805 
[8] Sène, D., Huong-Boutin, D.L.T., Thiollet, M., Barete, S., Cacoub, P. and Piette, J.-C. (2008) Symptomatic Adrenal Insufficiency Secondary to the Use of Cutaneous Topical Steroids for Skin-Bleaching. La Revue de Médecine Interne, 29, 1030-1033. https://doi.org/10.1016/j.revmed.2008.02.014

[9] Paton, J., Jardine, E., McNeill, E., Beaton, S., Galloway, P., Young, D., et al. (2006) Adrenal Responses to Low Dose Synthetic ACTH (Synacthen) in Children Receiving High Dose Inhaled Fluticasone. Archives of Disease in Childhood, 91, 808-813. https://doi.org/10.1136/adc.2005.087247

[10] Petit, A., Ludmann, C., Clevenbergh, P., Bergmann, J.F. and Dubertret, L. (2005) Skin Lightening and Its Complications in the African Population of Paris. International Association for Cosmetic Dermatology, Paris.

[11] Sobngwi, E., Lubin, V., Ury, P., Timsit, F.-J. Gautier, J.-F. and Vexiau, P. (2003) Adrenal Insufficiency and Diabetes Mellitus Secondary to the Use of Topical Corticosteroids for Cosmetic Purpose. Annales d Endocrinologie, 64, 202-204.

[12] Hoshawra, R.A., Zimmerman, K.G. and Mentera, A. (1985) Ochronosislike Pigmentation from Hydroquinone Bleaching Creams in American Blacks. Archives of Dermatology, 121, 105-108. https://doi.org/10.1001/archderm.1985.01660010109032

[13] Keane, F.M., Munn, S.E., Taylor, N.F. and Du Vivier, A.W. (2001) Unregulated Use of Clobetasol Propionate. British Journal of Dermatology, 144, 1095-1096. https://doi.org/10.1046/j.1365-2133.2001.04213.x

[14] Reznik, Y., et al. (2018) SFE/SFEDP Adrenal Insufficiency French Consensus: Introduction and Handbook. Annales d' Endocrinologie, 79, 1-22. https://doi.org/10.1016/j.ando.2017.12.001

[15] Kovacs, W.J. and Orth, D.N. (2000) Structure-Function Relationships of Synthetic Glucocorticoids. UpToDate, 8, 1-3. 